This is the peer reviewed version of the following article: Craig, A. and Corrall, S. (2007), Making a difference? Measuring the impact of an information literacy programme for preregistration nursing students in the UK. Health Information \& Libraries Journal, 24: 118-127, which has been published in final form at http://onlinelibrary.wiley.com/doi/10.1111/j.14711842.2007.00688.x/abstract.

This article may be used for non-commercial purposes in accordance With Wiley Terms and Conditions for self-archiving.

\title{
Making a difference? Measuring the impact of an information literacy programme for pre-registration nursing students in the UK.
}

\author{
Ann Craig, Head of Academic Liaison, Information \& Learning Services, University of \\ Worcester, Worcester, UK
}

Sheila Corrall, Professor of Librarianship \& Information Management, University of Sheffield, Sheffield, UK

\begin{abstract}
Objectives: Investigates whether an information literacy programme for pre-registration nursing students at a British higher education institution is effective in developing their skills and confidence: examines students' skill levels, factors affecting their confidence, and relationships between skills, confidence and demographic characteristics.

Methods: Quantitative and qualitative techniques were used: pre- and post-tests to measure changes in students' skills and self-assessed confidence levels after two key sessions in their first semester $(n=29)$; semi-structured interviews to explore factors affecting confidence $(n=5)$.

Results: Findings demonstrated positive impacts on skills and confidence. Key areas of skill development included: identifying journal articles, selecting search terms and evaluating website quality. Factors affecting confidence included: successful 'mastery' experiences in searching for information and the programme itself, especially small-group sessions, handouts and staff support. Evidence on links between skills, confidence and demographic factors was inconclusive.

Conclusions: The study demonstrated the programme's effectiveness and identified areas for development, including the need to help students understand the relative merits of search engines and other sources. Evidence has contributed to a change in departmental policy, making attendance at sessions mandatory. Further studies have been recommended.
\end{abstract}

Keywords

Academic libraries; Evaluation; Information literacy; Information skills; Nursing; Students; User education; User training.

\section{Introduction}

The ability to use information is "an integral component of professional practice" in the modern National Health Service (NHS). 1 The NHS Health Informatics Competency Profiles requires nurses to have 'advanced competency' in all Information Management topics.2 
Librarians have long recognised the need for information skills to be part of the nursing curriculum;3 nurses must have the opportunity to develop Information Literacy (IL) skills within their pre-registration courses, so that they become "discerning information consumers", acquire the knowledge and skills necessary for their roles, and recognise the need to become lifelong learners.4 The recent Information for Nursing and Health in a Learning Environment (INHALE) project highlighted a continuing need for nursing students to have IL learning opportunities within Higher Education (HE). 5

The setting for this study is a small higher education institution (HEI) in central England, where an IL programme was developed for Diploma in HE (DipHE) Nursing students. This programme is embedded across their three-year course, with three key three-hour sessions in their first semester: an induction and a session on information searching for the whole group, and a practical session, building on the latter, delivered to eight small groups.

The programme was developed in collaboration with academic colleagues, incorporating exercises designed to complement assessments in other units. It covers the first five pillars of the SCONUL IL model, aiming in Semester 1 to take students to the 'Advanced Beginners' level.6 (See Appendix 1 for the intended learning outcomes.)

This programme is resource-intensive, with two intakes annually. It was previously evaluated by subjective questionnaires, generating useful information, but no objective evidence of its impact on student learning, to provide a firmer base for changing the programme and ensuring effective resource utilisation. Institutional plans to increase student numbers and revalidate the course provided further impetus to obtain conclusive evidence of its value.

A high proportion of these DipHE students are 'non-traditional' entrants, with qualifications ranging from National Vocational Qualifications to degrees in other disciplines. Many have gaps in their education or have changed careers. Staff had observed that, overall, nursing students make more use of library support mechanisms, seeming less confident information users than students taking traditional undergraduate courses, but reasons for this were unclear. These students might simply lack confidence in their skills. Conversely, their requests for help could denote confidence, perhaps after identifying a knowledge gap through the IL programme, while those with little confidence might avoid asking for support.

Factors relating to confidence were thus another area for investigation, to ensure the programme developed confidence as well as skills and appropriate support was provided. The mixed profile of students also raised the possibility that demographic characteristics, such as age and gender, might influence skills and confidence.

\section{Objectives}

The primary aim of the study was to investigate whether this IL programme was effective in increasing students' skills and confidence. Time constraints limited its scope to the sessions in the students' first semester. Its specific objectives were to:

- test students' skill levels before and after two key sessions

- explore factors affecting their confidence

- identify any relationships between skills, confidence and demographic characteristics.

A secondary aim was to inform the development of the IL programme at the institution. We also hoped the findings would be of interest to other HEls with similar student groups. 


\section{Literature review}

The literature on IL is substantial: a 'select' bibliography for 2004 lists 270 items, including 159 on academic libraries.7 This review therefore concentrates on IL assessment and evaluation, including the rationale and methods for such studies; investigations of confidence and demographic characteristics in relation to IL; and the effectiveness of programmes for nursing students. In this article, the term 'assessment' is used specifically in relation to measuring student learning and 'evaluation' is used for the effectiveness of IL interventions.

Around $10 \%$ of publications on IL in 2004 were devoted to assessment and evaluation.7 Treatments include case studies, critical reviews and opinion pieces, as shown here. Several authors discuss the rationale and motivations for IL assessment and evaluation, identifying the following purposes:

- to define and measure students' skills;

- to develop benchmarking statements and quality standards;

- to evidence achievement of intended learning outcomes;

- to improve future programmes;

- to support the professional development of library staff;

- to involve library staff in the same quality mechanisms as academic staff;

- to develop more strategic, client-centred, outcomes-based indicators of library success.8-11

The range of assessment and evaluation methods discussed includes both quantitative and qualitative approaches, for example: pre-tests and post-tests; recall and precision exercises; multiple-choice questions (MCQs); skills checklists; satisfaction questionnaires; focus groups; interviews; self-assessments; longitudinal surveys, including surveys of graduates and their employers; observation; and examination of completed work, such as (annotated) bibliographies, concept maps, learning diaries and research portfolios.12-15 Some studies combine different methods to strengthen the evidence provided.16-18 Several authors found students' self-assessed ratings of their skills were higher than their scores in objective tests indicate, though Coupe found they could be accurate.19-23

Several studies discuss the use of pre- and post-tests, in various formats (e.g. print or electronic MCQs). These cover a range of subject areas and student levels.8,11,16-18,2432. Few studies publish their research instruments, but six of those cited do so, offering opportunities for replication and comparison.16,20,23,25-6,28.

There is less literature investigating confidence in using information than skills. Bandura's concept of 'self-efficacy' has been influential here. It identifies four dimensions of experience affecting individuals' beliefs in their ability to perform a particular task ('mastery experiences', 'vicarious experiences', 'social persuasion', 'physiological and emotional states').33 Several researchers have used this concept to explore the effects of IL interventions and illuminate issues surrounding confidence in information use. Ren used pre- and post-intervention questionnaires to investigate students' self-efficacy in electronic information searching.34 Kurbanoglu found a correlation between self-efficacy in information skills and computer skills, but discovered that belief and reality may differ, with talented performers lacking confidence and others over-estimating their abilities; one factor causing self-efficacy to diminish is the understanding of how much there is to learn.35 Other methods used to investigate confidence include interviews and self-assessments. 16-18,36

There is limited literature specifically addressing the effects of demographic characteristics on information skills and confidence, but some coverage in larger studies. Within nursing, there is some evidence of both age and gender differences. The literature suggests older 
learners have more difficulties in developing information skills and the period elapsed since formal education has an impact on skill levels; in addition, female students are less confident than male students and more anxious about using computers.37 One study found male students were more skilful in constructing search strategies. 20

Fox and colleagues have done seminal work in the field of nursing, including a large-scale multi-dimensional IL programme evaluation, which found improvements in both cognitive and affective domains. Methods used include informal questioning, graded assignments, selfreported data on attitude change and comparisons with other student groups, in addition to pre- and post-programme objective tests and confidence surveys.16 Shorten et al. also report extensive programme evaluations, demonstrating increases in both skills and confidence of nursing students.17 Martin reports benefits identified through evaluation via a reflective essay. 38 However, multi-method approaches used for nursing programmes elsewhere provided inconclusive evidence.27,39

\section{Methodology}

We used a mixed methods approach, combining quantitative techniques (objective pre- and post-tests and statistical analysis) to measure skills with qualitative techniques (semistructured in-depth interviews and rich descriptions) to explore factors affecting confidence. This strategy employed methods appropriate to the different issues examined and achieved a degree of triangulation to improve validity; the tests included questions on confidence levels and the interviews touched on skills in addition to confidence.

The planned test sample was the whole February 2005 intake $(n=76)$. For the interviews, the aim was to recruit a purposive sample of divergent cases, comprising around $10 \%$ of those who had completed both tests. Selection was based on skills scores and self-assessed confidence ratings, targeting students who were 'Very' or 'Not at all' confident and who recorded a significant or little change in their confidence levels. There was no control group for comparison: most intakes have some form of IL intervention and it would have been unethical to withhold such support. Approval was obtained from the institution's Ethics Committee.

Advantages of using pre- and post-tests include the likelihood that changes identified are attributable to the intervention, administration will be quick and cheap, and response rates high if timetabled into a class session. Disadvantages include an inability to measure longterm changes in behaviour, thereby not acknowledging a need for time to practise the skills learned.31 Interviews were considered the most appropriate way to collect in-depth, rich data about factors affecting confidence in the time available. Although time-consuming and possibly subject to bias, interviews allow researchers to "follow up ideas, probe responses and investigate motives and feelings, which the questionnaire can never do".40

The tests were developed from one recently introduced at the institution and used MCQs, which are familiar to students and easy to mark, but difficult and time-consuming to write.41 Fourteen questions covered topics taught in the semester, each question having only one correct answer. Both tests presented the same questions in the same order, but students were not told this in advance. The tests also asked respondents to rate their confidence in their ability to locate information on a four-point scale; in the post-test, they were asked to rate it at both the beginning of the course and the time of the test. The test and interview questions were rigorously piloted (with colleagues and students) and refined accordingly. (See Appendix 2-3 for questions used.)

Seventy students completed the pre-test, but only 29 completed both tests; the reduction reflects a change in departmental policy making attendance at these sessions no longer 
compulsory. Participants provided their student number to enable comparison of pre- and post-test scores. SPSS was used to obtain descriptive statistics and to test statistical significance (using non-parametric tests, the sample being under 30). Five interviews were conducted, exceeding the $10 \%$ target. Interviewees were sent the questions beforehand and interviews were tape-recorded. Interview data were transcribed and analysed for key themes.

\section{Results}

The sample completing both tests comprised 5 males and 24 females, with a mean age of 31.79 (12 aged 18-30, 14 aged 31-44 and three aged 45+). The small number of males and of representatives for each age group prevented any valid conclusions being drawn on the relationship of gender or age to skill or confidence.

\section{Skills}

The data were analysed, compared and tested to investigate the degree of change for each question, individual students and the whole group. Table 1 summarises the data in relation to answers for individual questions. (Percentages are rounded to whole numbers.)

Table 1 Frequency and percentage of correct answers

\begin{tabular}{llllll}
\hline Question & & \multicolumn{2}{c}{ Pre-test correct } & \multicolumn{2}{c}{ Post-test correct } \\
number & Topic & Frequency & $\%$ & Frequency & $\%$ \\
\hline 1 & Library catalogue & 27 & 93 & 27 & 93 \\
2 & Locating books & 16 & 55 & 21 & 73 \\
3 & Dewey scheme & 24 & 83 & 28 & 97 \\
4 & Dictionaries & 19 & 66 & 24 & 83 \\
5 & Textbooks & 22 & 75 & 14 & 48 \\
6 & Journals & 14 & 48 & 24 & 83 \\
7 & Interpreting citations & 19 & 66 & 23 & 79 \\
8 & Identifying articles & 24 & 83 & 27 & 93 \\
9 & Refining searches & 28 & 97 & 29 & 100 \\
10 & Selecting terms & 2 & 7 & 9 & 31 \\
11 & Boolean logic & 28 & 97 & 28 & 97 \\
12 & Truncation & 9 & 31 & 11 & 37 \\
13 & Evaluating websites a & 8 & 28 & 19 & 66 \\
14 & Evaluating websites b & 24 & 83 & 23 & 79 \\
\hline
\end{tabular}

The McNemar test was used to identify significant changes in the frequency of correct answers (adopting a confidence level of $95 \%$ ). Significant positive results were recorded for Q6, Q10 and Q13, and one significant negative result for Q5. Although not statistically significant, there was also some positive change for Q2-4 and Q7. The data revealed some patterns among incorrect answers, identifying points needing more attention in the IL programme, including specific techniques such as selecting search terms (Q10).

Twenty-one students (72\%) improved their scores, five (17\%) scored the same and three (10\%) performed worse. The data yielded much useful information about individuals, which was beyond the scope of this study, but could be explored in future research. Figure 1 compares pre- and post-test scores for the group: the mean scores were 9.10 and 10.59 respectively. The Wilcoxon signed ranks test showed that the change was statistically significant. 


\section{Cases}

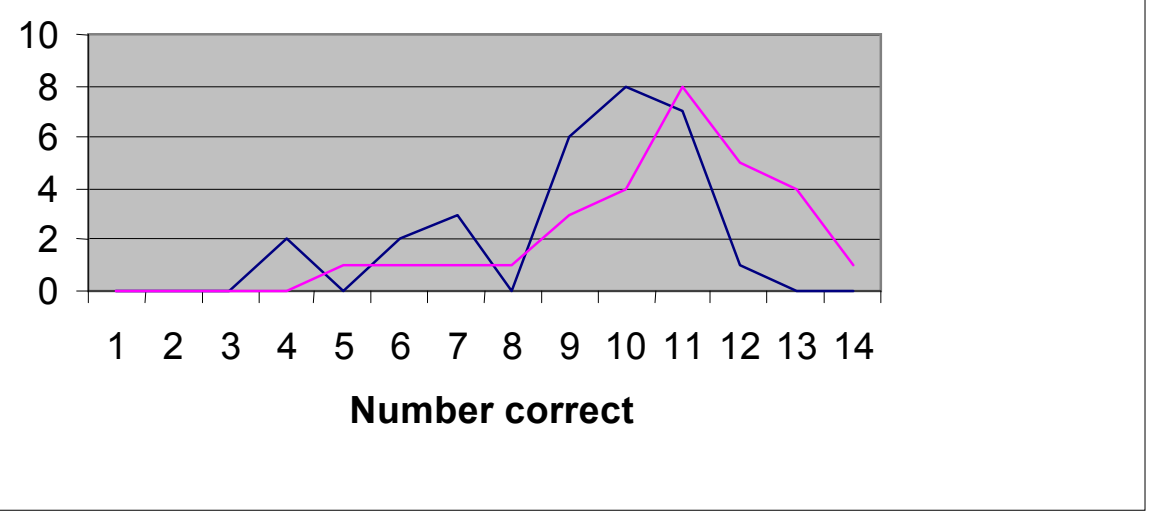

Figure 1 Comparison of scores

-, Pre-test; -, Post-test.

\section{Confidence}

The data showed an overall improvement in confidence with $28(97 \%)$ rating themselves 'Fairly' or 'Very' confident at the post-test, compared with $22(76 \%)$ previously. The main change was an increase from five $(17 \%)$ to ten $(34 \%)$ rating themselves 'Very confident'.

Figure 2 summarises the data. (One student did not answer Q16.)

\section{Frequency}

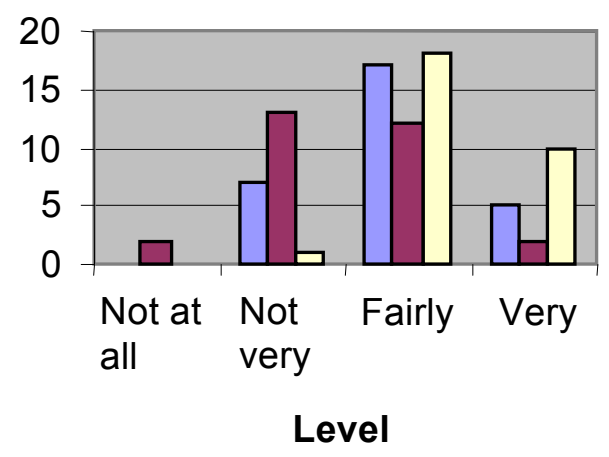

Figure 2 Confidence levels
口, Pre-test;
Post-test Q15;
口, Post-test Q16.

The frequency of 'Don't know' answers is another indicator of confidence. Seven students answered thus in the pre-test, compared with two in the post-test. These two both answered 'Don't know' four times in the pre-test and rated themselves 'Not very confident' at the pretest. At the post-test they answered 'Don't know' twice and rated themselves 'Fairly confident'. They also both improved their skills scores (by four and six respectively). 
Table 2 compares skills scores with confidence ratings, showing that students' stated confidence generally matched their skill levels at the pre-test. There were more discrepancies between confidence and skills at the post-test.

Table 2 Skill and confidence levels

\begin{tabular}{|c|c|c|c|c|c|c|c|c|c|}
\hline \multirow[b]{2}{*}{$\begin{array}{l}\text { Skill } \\
\text { score }\end{array}$} & \multicolumn{4}{|c|}{ Pre-test confidence rating } & \multicolumn{5}{|c|}{ Post-test confidence rating } \\
\hline & $\begin{array}{l}\text { Not } \\
\text { at all }\end{array}$ & $\begin{array}{l}\text { Not } \\
\text { very }\end{array}$ & Fairly & Very & $\begin{array}{l}\text { Not } \\
\text { at all }\end{array}$ & $\begin{array}{l}\text { Not } \\
\text { very }\end{array}$ & Fairly & Very & $\begin{array}{l}\text { Skill } \\
\text { score }\end{array}$ \\
\hline 4 & - & 2 & - & - & - & - & - & - & 4 \\
\hline 5 & - & - & - & - & - & - & 1 & - & 5 \\
\hline 6 & - & 1 & 1 & - & - & - & 1 & - & 6 \\
\hline 7 & - & 1 & 2 & - & - & - & - & - & 7 \\
\hline 8 & - & - & - & - & - & - & 1 & - & 8 \\
\hline 9 & - & 2 & 4 & - & - & - & 3 & - & 9 \\
\hline 10 & - & 1 & 5 & 3 & - & 1 & 3 & - & 10 \\
\hline 11 & - & - & 5 & 1 & - & - & 6 & 2 & 11 \\
\hline 12 & - & - & - & 1 & - & - & 2 & 3 & 12 \\
\hline 13 & - & - & - & - & - & - & 2 & 2 & 13 \\
\hline 14 & - & - & - & - & - & - & - & 1 & 14 \\
\hline Total & - & 7 & 17 & 5 & - & 1 & 19 & 8 & \\
\hline
\end{tabular}

The interviews explored factors potentially affecting confidence, including previous educational experiences. Table 3 shows the characteristics of the sample $(n=5)$. The lack of males and of students aged 18-30 means it did not fully reflect the demographics of the whole group, but it was representative in the range of skills scores and confidence levels recorded.

Table 3 Age, skills scores and confidence ratings of interview sample

\begin{tabular}{lllllll}
\hline Student & $\begin{array}{l}\text { Age } \\
\text { group }\end{array}$ & $\begin{array}{l}\text { Pre-test } \\
\text { score }\end{array}$ & $\begin{array}{l}\text { Pre-test } \\
\text { rating }\end{array}$ & $\begin{array}{l}\text { Post-test } \\
\text { score }\end{array}$ & $\begin{array}{l}\text { Post-test } \\
\text { rating Q15 }\end{array}$ & $\begin{array}{l}\text { Post-test } \\
\text { rating Q16 }\end{array}$ \\
\hline A & $45+$ & 12 & Very & 14 & Very & Very \\
B & $31-44$ & 6 & Fairly & 9 & Not very & Fairly \\
C & $45+$ & 10 & Not very & 9 & Not very & Fairly \\
D & $31-44$ & 4 & Not very & 8 & Not at all & Fairly \\
E & $31-44$ & 11 & Fairly & 12 & Not very & Fairly \\
\hline
\end{tabular}

The interviewees had diverse educational backgrounds and three had gaps of ten years or more since their previous course. Four used the Internet to find information in their personal lives and three had some Internet search training in previous courses. They had been surprised by the amount of IL input to their present course, particularly students $C$ and D:

"I didn't realise there'd be as much as there was. Essays to me were you'd write down what you'd learned, not all this referencing other people's views and ideas so that was quite a shock...It's quite daunting, especially if you're older." (Student C)

I think I was a bit naïve actually...I thought you'd be attending your lectures... Nowhere was I thinking it's access www-dot-slash. It completely put me on edge." (Student D)

When asked how they felt starting the course, $B$ and $C$ rated themselves 'Not at all confident', which was lower than their test assessments. A and $E$ mentioned previous 
success in using the Internet and/or libraries as factors giving them confidence. B and D mentioned lack of IT experience as a negative factor.

When asked about their present confidence levels, B, C and D reported an increase (to 'Fairly confident'), while A and E maintained theirs. B, D and E reported dips in confidence during the IL programme, associated respectively with a particular session, information overload and the first assignment. However, D was "quite proud of myself for what l've managed to achieve".

Positive influences on confidence included successful application of new skills learned (e.g. searching for journal articles and selecting search terms) and the availability of support mechanisms to reinforce learning (e.g. handouts and help). Negative factors included password problems and insufficient time to progress research and practise skills. The main strategy identified to counteract low confidence was asking others for help (e.g. library staff, fellow students, family and friends). Other points emerging were the perceived benefits of small-group sessions, requests for conducted tours of the library (including the journals area) and appreciation of the library staff's approachability.

Key influences on confidence levels thus included: previous and current experiences of using IT, the Internet and (to a lesser extent) libraries; and the programme itself, including the skills learned, feedback from small-group sessions, handouts and availability of help. There was no conclusive evidence on the influence of age: $B$ and $C$ mentioned age as a factor affecting their confidence, but in the specific context of lacking computer skills; whereas A (aged 45+) remained 'Very confident' throughout the study.

\section{Discussion}

The results demonstrate that the IL programme was effective in developing students' ability to identify, locate and evaluate information. This evidence of its positive effect on nursing students' skills is similar to findings elsewhere.16-17

Table 1 shows higher scores for ten questions, no change for two questions (where scores were already high) and lower scores for two questions. For Q14 the change was marginal, but for Q5 correct answers dropped from 22 (75\%) to 14 (48\%): nine students in the posttest and five in the pre-test chose 'An Internet search engine' as the best source for a wellestablished introduction to a subject (instead of 'A textbook'). Although disappointing, this result reflects other findings that Google is often students' preferred starting point for research.42 The same answer was also the most frequent incorrect response to Q4 and Q6, reinforcing this view. The biggest percentage improvements in scores were for questions relating to journals (40\%), website evaluation (38\%) and database search terms $(24 \%)$, which is consistent with interview data identifying searching for journal articles and selecting search terms among the new skills seen as confidence-boosters by interviewees.

The results similarly show improvements in confidence levels between pre- and post-tests (evident in higher self-assessed ratings and lower frequency of 'Don't know' answers), which also confirm the positive impacts on confidence reported in the literature.11,16-18,36.

Interview data identified some positive influences on confidence (notably previous success in Internet searching and the IL programme itself), but also some dips in confidence, reinforcing findings elsewhere.35 The interviews also provided evidence of the students' self-efficacy, including high levels arising from successful 'mastery experiences' and a range of levels shown in comments on their 'physiological and emotional states'.33 
The test data suggested some relationship between skills and confidence levels, but results were inconsistent. The pre-test alignment of self-assessments with performance levels supports Coupe's findings, 23 but the post-test disparities reinforce the prevalent view that students tend to over-estimate their skills.11,19-22 However, the student with the lowest post-test confidence rating had a higher skills score than six students rating themselves at the next level, illustrating that confidence is personal to the individual and difficult to assess.

Limitations of the study

The timing of the tests limited the study to a snapshot of short-term programme impacts and the lack of a control group weakened its validity. The reduced sample size limits the weight of the evidence and the smaller pool of students available for interview invalidated the investigation of demographic factors.

The wording and format of the questions may have influenced the results. Terminology may have been misunderstood and the descriptors for confidence ratings were open to different interpretations. For some questions, there was arguably more than one right answer and it might have been better to ask participants to rank options, rather than tick one. Some students may have achieved correct answers by guesswork. The interviews were conducted by one of the teaching team, which could have influenced results. Outside influences may also have had an effect, if students discussed questions with others between the tests. (This could be remedied by using the same questions, but with different examples.)

The test instruments were developed in-house and have not been assessed for reliability and validity using external indices. Some of the questions are subject-specific and would not be transferable to another discipline without re-writing.

\section{Conclusions}

The study met its objectives, demonstrating a positive change in skill and confidence levels after the IL sessions and revealing factors affecting confidence positively and negatively. Key findings centre on the programme's contribution to students' capacity to access academic literature and evaluate information quality. Links between skills and confidence proved difficult to articulate, but the programme evidently has a crucial role in helping students become independent information searchers. The study revealed the influence of 'mastery' experiences on confidence, provided through small-group sessions and library staff support. The sample composition precluded investigation of any relationships between skills, confidence and demographic characteristics.

The findings suggested the programme could be strengthened by placing more emphasis on the relative merits of Internet search engines and other information sources, opportunities for practice and feedback in small-group settings, and library tours as part of induction.

The study has illuminated the strengths and weaknesses of IL assessment and evaluation methods, prompting these recommendations:

- a longitudinal investigation of the IL skills and behaviour of DipHE Nursing students from induction to completion, with more in-depth exploration of individual cases;

- use of the pre- and post-tests with students from other disciplines, re-writing some questions to change the subject context and remedy identified problems.

There have already been positive outcomes: we have used quantitative and qualitative evidence to argue successfully for IL sessions to be mandatory and to plan programme 
enhancements. Our results should be of wider interest; the methodology is transferable to other settings and sharing of instruments could enable inter-institutional comparisons.

\section{Key messages}

Implications for Policy

- IL sessions should be mandatory to ensure maximum benefit to students and costeffective use of library staff. Library and academic staff need to collaborate in explaining their importance to students.

- Combining different evaluation methods provides a richer and more reliable evidence base.

- Sharing of research instruments would reduce the time required to draft questions and enable valuable replication of studies.

Implications for Practice

- Small-group sessions offering opportunities for practice and feedback are particularly effective in developing students' skills and confidence.

- Many students need to develop better understanding of when to use Internet search engines and when to use other information sources.

- Students' confidence in their ability to locate, evaluate and use information is often not an accurate reflection of their skill levels.

\section{Acknowledgements}

The authors wish to thank the University of Worcester for supporting the study, library staff at the University for their advice and assistance, and the student participants for their time.

\section{Supplementary material}

The following supplementary material is available for this article online:

Appendix 1: Information literacy programme: intended learning outcomes

Appendix 2: Information literacy quiz (pre-test and post-test questions)

Appendix 3: Interview schedule

\section{References}

1. NHS Information Authority. Health Informatics: Nurses and Midwives. Available from: http://www.nhsia.nhs.uk/informatics/profiles/nursesmidwives.asp (accessed 6 August 2006). 2. NHS Information Authority. Health Informatics Competency Profiles for the NHS. Winchester: NHSIA, 2001. Available from: http://www.nhsia.nhs.uk/nhid/pages/resource_informatics/hi_competencyprofiles.pdf (accessed 6 August 2006).

3. Wakeham, M. Information skills in nurse education. Nursing Standard 1990, 5, 35-7.

4. Cheek, J. and Doskatsch, I. Information literacy: a resource for nurses as lifelong learners. Nurse Education Today 1998, 18, 243-50 (p243).

5. Brook, J., Pattern, D. and Anderson, S. The INHALE (Information for Nursing and Health in a Learning Environment) project. Vine 2005, 35, 28-38.

6. SCONUL The Seven Pillars of Information Literacy. Available from:

http://www.sconul.ac.uk/activities/inf_lit/seven_pillars.html (accessed 6 August 2006). 
7. Johnson, A.M. and Jent, S. Library instruction and information literacy. Reference Services Review 2005, 33, 487-530.

8. Bober, C., Poulin, S. and Vileno, L. Evaluating library instruction in academic libraries: a critical review of the literature. Reference Librarian 1995, 51/52, 53-71.

9. lannuzzi, P. We are teaching, but are they learning: accountability, productivity and assessment. Journal of Academic Librarianship 1999, 25, 304-305.

10. Davidson, J.J., McMillen, P.S. and Maughan, L.S. Using the ACRL Information Literacy Competency Standards for Higher Education to assess a university library instruction program. Journal of Library Administration 2002, 36, 97-121.

11. Knight, $L$. The role of assessment in library user education. Reference Services Review 2002, 30, 15-24.

12. Pausch, L.M. and Popp, M.P. Assessment of information literacy: lessons from the higher education movement. Association of College and Research Libraries. Choosing Our Futures: $8^{\text {th }}$ National Conference, 11-14 April, Nashville, Tennessee, 1997. Available from: http://www.ala.org/ala/acrlbucket/nashville1997pap/pauschpopp.htm (accessed 6 August 2006).

13. Williams, J. Creativity in assessment of library instruction. Reference Services Review 2000, 28, 323-34.

14. Rockman, I.F. Strengthening connections between information literacy, general education, and assessment efforts. Library Trends 2002, 51, 185-98.

15. Brettle, A. and Greenhalgh, J. Made to measure: developing a template to assess the effectiveness of information skills training. CILIP Health Libraries Group. Variety is the Spice of LIFE (Libraries and Information for Evidence), Conference, 6-8 September, Belfast, 2004. Available from:

http://www.cilip.org.uk/groups/hlg/conf2004/presentations/Brettle\%20and\%20Greenhalgh.pp $\mathrm{t}$ (accessed 6 August 2006).

16. Fox, L.M., Richter, J.M. and White, N.E. A multidimensional evaluation of a nursing information-literacy program. Bulletin of the Medical Library Association 1996, 84, 182-90.

17. Shorten, A., Wallace, M.C. and Crookes, P.A. Developing information literacy: a key to evidence-based nursing. International Nursing Review 2001, 48, 86-92.

18. Julien, H. and Boon, S. Assessing instructional outcomes in Canadian academic libraries. Library and Information Science Research 2004, 26, 121-39.

19. Greer, A., Weston, L. and Alm, H. Assessment of learning outcomes: a measure of progress in information literacy. College and Research Libraries 1991, 52, 549-57.

20. Fox, L.M. and Weston, L. Course-integrated instruction for nursing students: how effective? Research Strategies 1993, 11, 89-99.

21. Maughan, P.D. Assessing information literacy among undergraduates. College and Research Libraries 2001, 62, 71-85.

22. Brown, C., Murphy, T.J. and Nanny, M. Turning techno-savvy into info-savvy: authentically integrating information literacy into the college curriculum. Journal of Academic Librarianship 2003, 29, 386-98.

23. Coupe, J. Undergraduate library skills: two surveys at Johns Hopkins University. Research Strategies 1993. 11, 188-201.

24. Francis, B.W. and Fisher, C.C Multilevel library instruction for emerging nursing roles. Bulletin of the Medical Library Association 1995, 83, 492-8.

25. Colborn, N.W. and Cordell, R.M. Moving from subjective to objective assessments of your instruction program. Reference Services Review 1998, 26, 125-37.

26. Lawson, M.D. Assessment of a college freshman course in information resources. Library Review 1999, 48, 73-8.

27. Verhey, M.P. Information literacy in an undergraduate nursing curriculum: development, implementation and evaluation. Journal of Nursing Education 1999, 38, 252-9. 
28. Smalley, T.N. Do Students Actually Become Better Researchers Through Information Literacy Instruction Supported by Class Sessions in the Library? Assessing Learner Outcomes in a Lower Division Anthropology Course. 2000. Available from: http://www.cabrillo.edu/services/instruction/learneroutcome/tsmalley.pdf (accessed 6 August 2006).

29. Rosenfeld, P., Salazar-Riera, N. and Vieira, D. Piloting an information literacy program for staff nurses: lessons learned. CIN Computers, Informatics, Nursing 2002, 20, 236-41. 30. Jacobs, S.K., Rosenfeld, P. and Haber, J. Information literacy as the foundation for evidence-based practice in graduate nursing education: a curriculum-integrated approach. Journal of Professional Nursing 2003, 19, 320-28.

31. Salisbury, F. and Ellis, J. Online and face-to-face: evaluating information literacy skills to undergraduate arts students. Library Review 2003, 52, 209-217.

32. Badger, J. and Roberts, S. Finite questions and infinite answers: online assessment of information literacy skills. Australian Library and Information Association. Information Online 2001: Digital Dancing: New Steps, New Partners, $10^{\text {th }}$ Exhibition and Conference, 16-18 January, Sydney, Australia, 2001. Available from:

http://conferences.alia.org.au/online2001/papers/information.literacy.strategies.c.html (accessed 6 August 2006).

33. Bandura, A. Self-efficacy: towards a unifying theory of behavioural change.

Psychological Review 1977, 84, 191-213.

34. Ren, W.H. Library instruction and college student self-efficacy in electronic information searching. Journal of Academic Librarianship 2000, 26, 323-8.

35. Kurbanoglu, S.S. Self-efficacy: a concept closely linked to information literacy and lifelong learning. Journal of Documentation 2003, 59, 635-46.

36. Branch, J.L. Nontraditional undergraduates at home, work and school: an examination of information-seeking behaviours and the impact of information literacy instruction. Research Strategies 2003, 19, 3-15.

37. Cole, I.J. and Kelsey, A. Computer and information literacy in post-qualifying education. Nursing Education in Practice 2004, 4, 190-99.

38. Martin, S. Reflections on a user education session with nursing students. Health Libraries Review 1998, 15, 111-6.

39. Roselle, A. Using the ALA's Evaluating Library Instruction. Journal of Academic Librarianship 1997, 23, 390-97.

40. Bell, J. Doing Your Research Project. $3^{\text {rd }}$. ed. Buckingham: Open University Press, 1999 (p135).

41. Brown, S. and Knight, P. Assessing Learners in Higher Education. London: Kogan Page, 1994.

42. Griffiths, J. and Brophy, P. Student behaviour and the web: use of academic resources and Google. Library Trends 2005, 53, 539-54. 